\title{
Development of a retractable tray dryer for drying crops in solar PV farms
}

\author{
*Ya'acob M.E. and Mohamad, U. \\ Department of Process and Food Engineering, Faculty of Engineering, Universiti Putra Malaysia, 43400 \\ Serdang, Selangor, Malaysia
}

\begin{abstract}
Article history:
Received: 3 August 2018

Received in revised form: 13

September 2018

Accepted: 20 September 2018

Available Online: 6

November 2018
\end{abstract}

Keywords:

Retractable tray dryer,

Dissipated heat,

Air convection,

Crops drying.

DOI:

https://doi.org/10.26656/fr.2017.2(6).137

\begin{abstract}
Temperature plays a significant element in Solar PV technology as well as herbal growth. Significant research laboratories have proven that approximately $0.5 \%$ electricity from PV generators are reduced based on $1{ }^{\circ} \mathrm{C}$ increase of the module temperature which is dispersed as heat energy whereas increasing temperature may degrade the plant growth. Harvesting the dissipated heat from the bottom surface of a Photovoltaic (PV) Array is currently a new research area which is in line with sustainable urban development. This study suggested a new prototype of Retractable Tray Dryer (RtD) be embedded directly under PV arrays as means of harvesting the dissipated heat as well as reducing the bottom temperature within the concept of heat convection. The tray dryer is designed in such a way that it can be suited to any PV structures and can be clustered for a large scale farm. A specified leavy-type herbal crop was used as sample and tested at the Universiti Putra Malaysia PV Pilot site. Field test of the embedded tray as compared to the normal system showed higher drying rate for RtD which produces higher yield and good quality of dried crops.
\end{abstract}

\section{Introduction}

Most of the Sun's heat is used in evaporation and precipitation formation and the temperature in the tropics rarely exceeds $35^{\circ} \mathrm{C}$ whereas during the daytime, a maximum of $32^{\circ} \mathrm{C}$ is more common. During night time, the advantage of scattered clouds coverage prevents heat loss with the minimum temperature of $22^{\circ} \mathrm{C}$ (Osman et al., 2017). Based on the mechanisms of heat transfer, drying is categorized into direct (convection), indirect or contact (conduction), radiant (radiation) and dielectric or microwave (radio frequency) drying (Cengel, 2006; Sahni and Chaudhuri, 2012).

An alternative to this traditional method, many have suggested using mechanical solar drying system in which temperature, relative humidity $(\mathrm{RH})$ and air flow rate can be controlled to produce good quality of the final product. One of the conventional drying systems is using a flatbed dryer where products are filled in a box and heated from below. Such a system has the demerit of making uneven final moisture content where the grains in the bottom layer prone to dry faster than grains in the top layer (Chan et al., 2015). The drying process is an important process to control the inhibition of microorganisms and the reaction rate of degrading enzyme which affects the quality of the dried product. Since the drying process requires a lot more energy, direct-sun drying is widely used in rural areas for drying agricultural crops because the process is cheap especially in large-scale drying (Iskandar et al., 2017).

The theory of solar PV energy conversion can be classified broadly as the basis of dual nature of solar radiation, i.e. particle and wave nature. While assuming the solar radiation to be particle nature, the photons of energy greater than and equal to the energy band gap of the solar PV cell are the source for the electric energy generation. Whilst, the energy difference between the band gap and higher energy photons are contributing to the heat energy through the thermal process (Rawat et al., 2017).

According to Latiff et al. (2017), the alternative strategies and other continuous support to promote renewable energy would be the best solution to mitigate negative impacts of climate change especially harvesting the abundance of sun power via solar photovoltaic (PV) technologies. It is a known fact that PV module's efficiency decreases significantly with respect to increasing surrounding temperature (Tsay et al., 2011; Ye et al., 2013). 
Sun and Wang (2012) analyzed the heat transfer of a concentrating solar PV system as shown in Figure 1 where from the simulation result, the concentrating PV system with back channel higher is recommended for the dryer system because of its lower heat loss.

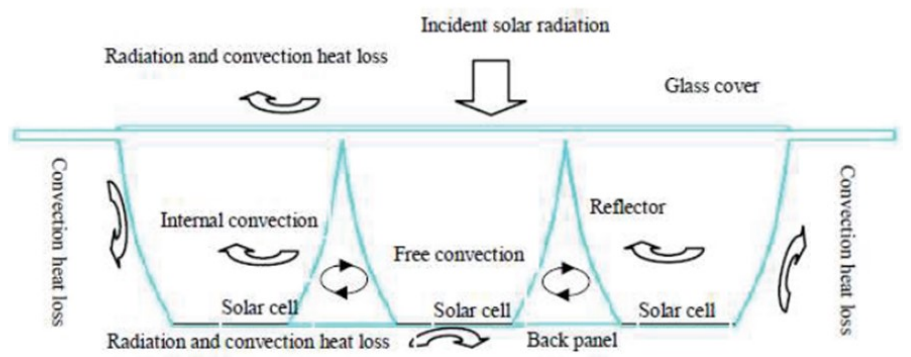

Figure 1. Schematic diagram for heat transfer under the PV solar panel

The direct - sun is the most common technique in drying system where this energy allows the free system to be constructed for thermal conversion mode adapted in the rural areas for crop drying applications (Zaid, 1999). The moisture is removed by the solar heated air having temperature range of $50^{\circ} \mathrm{C}$ to $60^{\circ} \mathrm{C}$. Solar drying under controlled conditions of temperature and moisture (removing rate) ensures desirable drying and product quality (Hii and Law, 2012). For a typically polycrystalline type PV panel, the solar-to-electrical conversion efficiency is about $13-18 \%$ and the remaining solar energy will be converted into waste heat which needs to be dissipated to avoid panel heating. The negative effect of PV panel heating is the declination of solar-to-electrical conversion efficiency $\left(-0.5 \%\right.$ per $\left.{ }^{\circ} \mathrm{C}\right)$ (Akbarzadeh, 1992). From the article on Honsberg and Bowden (2018), the excessive heat can reduce the energy output of a PV array, plus affects from seasonal weather variations; speed wind and cloud seeding. For a typical commercial PV array, around 10 to $15 \%$ will convert into electricity and the remaining will be converted into heat waste (Royne et al., 2005). The heat dissipation under PV array occurs mainly through the radiation process when the excessive heat is transferred to the surrounding environment causing the surface temperature on the bottom side of PV modules became much higher. Besides, the waste of heat on the PV panel will be used to dry the crop to reduce the emission of energy. At an insolation of $750 \mathrm{Wm}^{-2}$ ambient temperature of $23^{\circ} \mathrm{C}$, the $\mathrm{PV}$ cell temperature can rise above $45^{\circ} \mathrm{C}$. Thus, the heating of the PV panel will produce excess heat and this condition can be harvested for drying crops under the solar PV panels. The main objective of this study is to develop a new prototype of Retractable Tray Dryer (RtD) to be embedded directly under PV arrays as means of harvesting the dissipated heat as well as reducing the bottom temperature in crops drying process.

\section{Materials and methods}

\subsection{Development of retractable tray dryer}

A retractable tray dryer system had been installed under the PV solar panel at the site in front of Dewan Banquet of University Putra Malaysia, Serdang, Malaysia as shown in Figure 2. It had four parameter sensors to measure ambient temperature, relative humidity, wind velocity and direction, and solar radiation. The detail schematic layout of RtD is described in Figure 3. In the constant-rate period for the drying process, the water is being evaporated from what is effectively a free water surface. The rate of removal of water can then be related to the rate of heat transfer (no change in the temperature of the material) and therefore all heat energy transferred to it must result in evaporation of water. The rate of removal of the water is also the rate of mass transfer, from the solid to the ambient air (Earle, 1983). The drying rate calculation is based on Penman calculation as described in Equation 1 below.

$$
E=\frac{\left(P_{v p} A\right)(0.447 W)^{0.78}}{T+459.67}
$$

Where:

$\mathrm{E}=$ Evaporation rate $($ Gallons/Day)

$\mathrm{A}=$ Surface $\operatorname{area}\left(\mathrm{ft}^{2}\right)$

$\mathrm{W}=$ Wind Speed $(\mathrm{mph})$

$\mathrm{P}=$ Water vapor pressure $(\mathrm{mmHG})$ at ambient temperature

$\mathrm{T}=$ Temperature $\left({ }^{\circ} \mathrm{C}\right)$

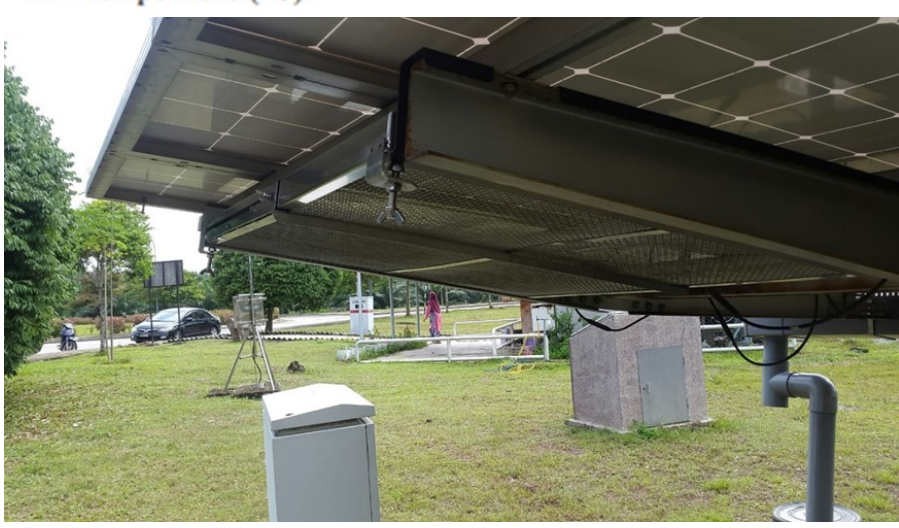

Figure 2. Retractable Tray Dryer tested under the PV panels at University Putra Malaysia

The PV tray dryer encompasses a lightweight aluminum box structure with dimensions of $0.855 \mathrm{~m}(\mathrm{~L})$ x $0.73 \mathrm{~m}(\mathrm{~W}) \times 0.04 \mathrm{~m}(\mathrm{H})$ and can hold a load capacity of $300-3000 \mathrm{~g}$ of crop depending on the types of the crops. For sample preparation, as shown in Figure 4, 300 g Misai kucing leaves were plucked and $150 \mathrm{~g}$ of the sample was placed on a dryer tray for both methods. After the drying process, the samples were weighed again to record the final weight. The final weight of sample dried with direct sun method was $22 \mathrm{~g}$ and the weight of sample dried with retractable PV tray dryer method was $50 \mathrm{~g}$ for $6 \mathrm{hrs}$ drying time. The dried sample properties such as color and texture of both methods were evaluated and compared. 

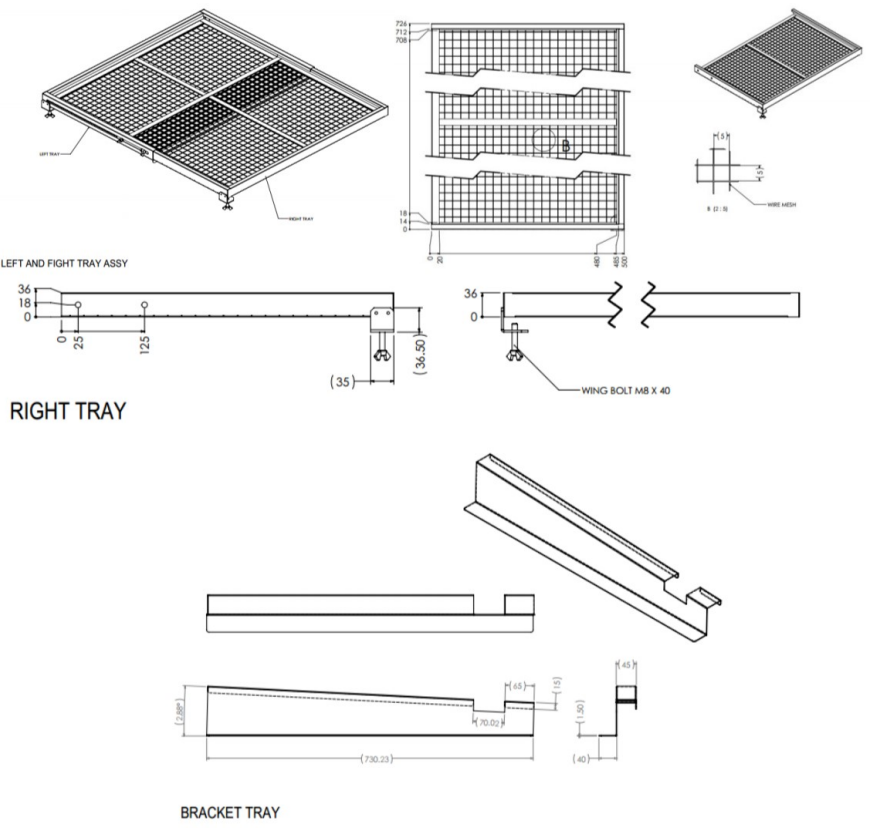

Figure 3. The schematic drawing of the retractable tray dryer (RtD).

\section{Results and discussion}

The plotted sample data for temperature performance of the experiments are shown in Figure 5 where $\mathrm{FFb}$ is the bottom surface of PV panel, FFs is the upper surface of $\mathrm{PV}$ panel, $\mathrm{T}_{\text {tray }}$ is drying retractable tray temperature and $\mathrm{Ta}$ is the ambient temperature.

The temperature data were recorded for five days continuously at 1 minute's intervals. The bottom surface of $\mathrm{PV}$ reaches the maximum temperature value up to $70^{\circ} \mathrm{C}$ on the bottom surface $\mathrm{PV}(\mathrm{FFb})$ and $65^{\circ} \mathrm{C}$ on the top surface of PV TC (FFs) during sun peak hour. The efficiency of the PV module will drop as there's high thermal energy waste from the solar module, especially when the module temperature reaches its maximum value.

The plotted data in Figure 6 have been carried out on site where the temperature on the tray $\left(T_{\text {tray }}\right)$ is higher as compared to the temperature ambient (Ta). The high temperature on the tray proves that there was a significant heat energy released under the PV array.

By using Equation (1), the result shows that the drying rate at the temperature below PV arrays on the retractable tray are faster than the drying rate at surrounding ambient temperature. The average of the drying rate for 1 day at FFmid is 28.796 g. $\mathrm{H}_{2} \mathrm{O} / \mathrm{h} . \mathrm{m}^{2}$ and the average of the conventional tray at ambient temperature is 12.953 g. $\mathrm{H}_{2} \mathrm{O} / \mathrm{h} \cdot \mathrm{m}^{2}$. ANOVA regression analysis of the 3471 data samples produces significant results of correlation coefficient, $\mathrm{R}^{2}=0.97$ which shows a good reliability of data captured. The retractable tray dryer shows higher drying rate as compared to the conventional direct sun drying. From the PV module, the

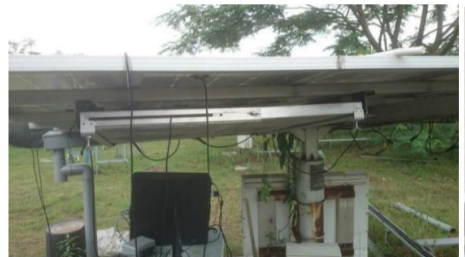

(a)

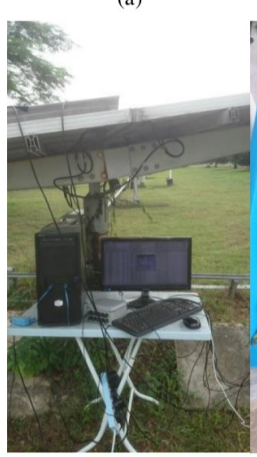

(c)

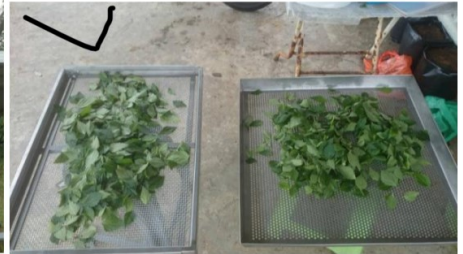

(b)
Figure 4. (a) Thermocouple sensor positioning; (b) Sampling tray, PV tray (left), drying tray (right); (c) System monitoring in real-time; (d) Color comparison on sample RtD (left) and conventional dryer tray (right)

waste energy released is potential to be utilized for drying system with some modification to the existing systems.

Temperature difference on PV surface and bottom

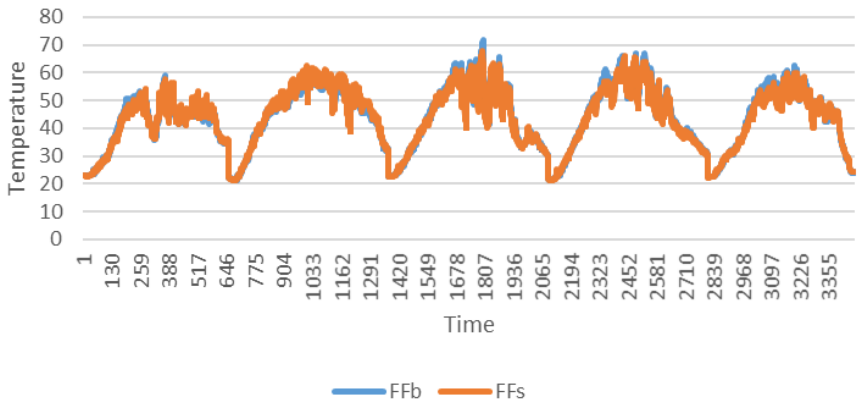

Figure 5. The temperature difference on the surface and bottom of the PV arrays

Temperature

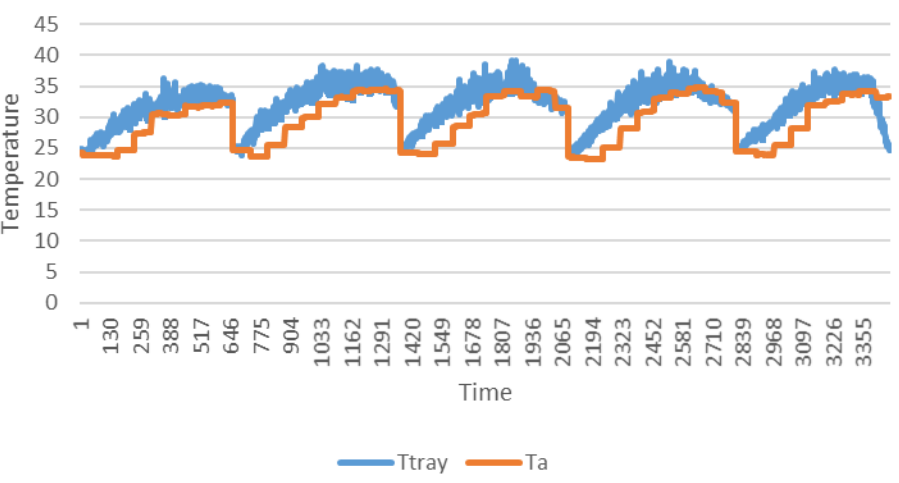

Figure 6. Plotted temperature data to evaluate the effect on temperature of PV surfaces on the tray drying. 


\section{Conclusion}

From the field evaluation, the high temperature values recorded underneath the PV array produces higher dissipated heat energy to the surrounding. The Retractable tray Dryer (RtD) is designed and developed to optimally harvest the heat energy for agricultural purpose in such a way that it can be suited to any PV structures and can be clustered for a large-scale farming. Based on field data, it is proven that drying herbal crops using the Retractable Tray (RtD) produces higher yield as compared to normal direct-sun drying. This concept can be proposed to improve the green energy utilization and optimize the drying efficiency with higher crops yield.

\section{Acknowledgement}

The authors delegate their thanks to the Research Management Centre (RMC), Universiti Putra Malaysia for the approval of research funding under the IPB Putra Grants Scheme (Vote no: 9515303).

\section{References}

Akbarzadeh A. (1992). Fundamentals of Remote Area Power Supply Systems: A text for tertiary students, p. 136. Melbourne, Australia: Renewable Energy Authority of Victoria.

Chan, Y., Dyah, T.N. and Kamaruddin, A. (2015). Solar dryer with pneumatic conveyor. Energy Procedia, 65, 378-385. https://doi.org/10.1016/ j.egypro.2015.01.067

Earle, R.L. (1983). Drying. In Units Operations in Food Processing, 2nd ed. USA: Elsevier. https:// doi.org/10.1016/B978-0-08-025536-1.50011-4

Iskandar, A.N., Ya'acob, M.E. and Anuar, M.S. (2017). Tropical field performance of dual-pass PV tray dryer. In AIP Conference Proceedings, 1885(1), 020016. https://doi.org/10.1063/1.5002210

Hii, C.L. and Law, C.L. (2012). Solar drying of major commodity products. In Hii, C.L., Jangam, S.V., Ong, S.P. and Mujumdar, A.S. (Eds.). Solar drying: Fundamentals, Applications and Innovations, p. 7394. Retrieved from website: https:// www.arunmujumdar.com/file/Publications/books/ Solar\% 20Drying_Fundamentals_Applications_and_Innovati ons.pdf

Honsberg, C. and Bowden, S. (2018). Heat Generation in PV Modules. Retrieved from PVeducation.org website: http://www.pveducation.org/pvcdrom/ modules/heat-generation-in-pv-modules.

Sahni, E.K. and Chaudhuri, B. (2012). Contact drying: A review of experimental and mechanistic modeling approaches. International Journal of Pharmaceutics, 434(1-2), 334-348. https:// doi.org/10.1016/j.ijpharm.2012.06.010

Latiff, N.A., Ya'acob, M.E. and Yunos, K.F.M. (2017). Conceptual approach on harvesting PV dissipated heat for enhancing water evaporation. In AIP Conference Proceedings, 1885(1), 020014. https:// doi.org/10.1063/1.5002208

Osman, F.A., Ya'acob, M.E. and Iskandar, A.N. (2017). Field measurements of temperature profile for floatovoltaic dryer in the tropics. AIP Conference Proceedings, 1885(1), $020015 . \quad \mathrm{https} / /$ doi.org/10.1063/1.5002209

Rawat, R., Lamba, R. and Kaushik, S. C. (2017). Thermodynamic study of solar photovoltaic energy conversion: An overview. Renewable and Sustainable Energy Reviews, 71, 630-638. https:// doi.org/10.1016/j.rser.2016.12.089

Royne, A., Dey, C.J. and Mills, D.R. (2005). Cooling of photovoltaic cells under concentrated illumination: a critical review. Solar Energy Materials and Solar Cells, 86(4), 451-483. https://doi.org/10.1016/ j.solmat.2004.09.003

Sun, J., and Wang, Y. (2012). Numerical Simulation of Heat Transfer of a Concentrating Solar Photovoltaic System. 2012 Asia-Pacific Power and Energy Engineering Conference, Shanghai. IEEE Conference Proceedings, 1-4. https:// doi.org/10.1109/APPEEC.2012.6307185

Tsay, Y.L., Cheng, J.C., Hong, H.F. and Shih, Z.H. (2011). Characteristics of heat dissipation from photovoltaic cells on the bottom wall of a horizontal cabinet to ambient natural convective air stream. Energy, 36(7), 3959-3967. https://doi.org/10.1016/ j.energy.2011.05.008

Cengel, Y.A. (2006). Heat and Mass Transfer: A Practical Approach. $3^{\text {rd }}$ ed. Europe: McGraw-Hill Education.

Ye, J., Ding, K., Reindl, T. and Aberle, A. G. (2013). Outdoor PV module performance under fluctuating irradiance conditions in tropical climates. Energy Procedia, 33, 238-247. https://doi.org/10.1016/ j.egypro.2013.05.064 